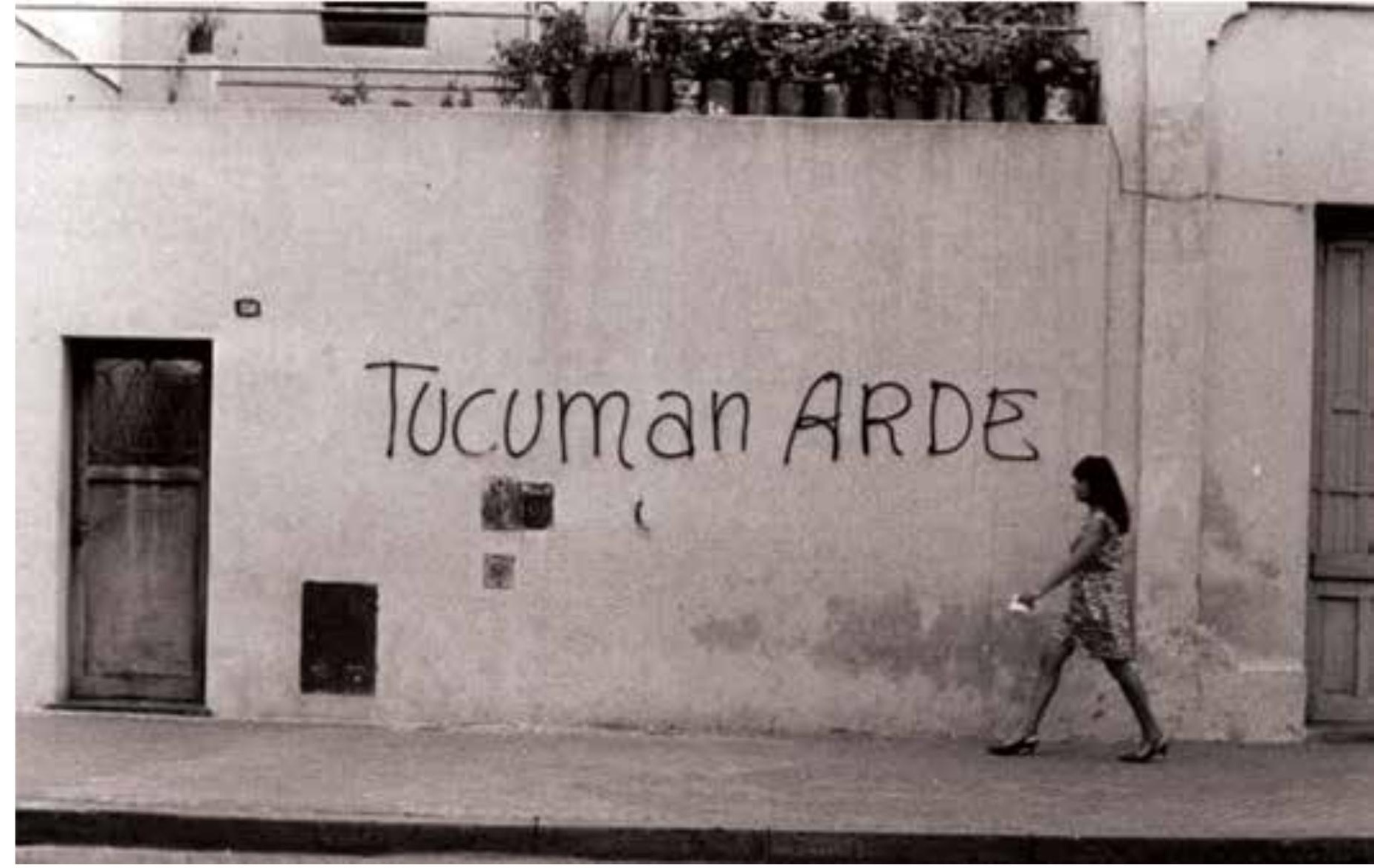

Edgardo-Antonio Vigo

Tucumán Arde

Argentina, 1970

\title{
MUSEUS DE ARTE CONTEMPORÂNEA: ENTRE BANCOS DE DADOS E NARRATIVAS I
}

\section{Cristina Freire}

\section{Resumo}

O caráter documental das práticas artísticas define um dos principais paradigmas da arte contemporânea. A relação entre obra de arte e documentação indica os paralelos entre museu e arquivo, narrativas e banco de dados.

\section{Palavras-chave:}

Arte Contemporânea; Museu; Arquivo; Arte Conceitual; Banco de Dados

\section{Abstract}

The documental character of the artistic practices defines one of the main paradigms of contemporary art. The relationship between work of art and documentation suggests the parallels between museum and archives, as well as narratives and data banks.

\section{Keywords:}

Contemporary Art; Museum; Archive; Conceptual Art; Data Bank 
1. Em meados da década de 1930, Marcel Duchamp anotou em um pedaço de papel: "usar um Rembrandt como uma tábua de passar". Sucinto na frase e explosivo em seu efeito iconoclasta, esse readymade invertido coloca de ponta cabeça toda e qualquer definição de obra de arte. 0 registro dessa ideia embaralha o que se tinha como certo: arte é para ver. Sua repercussão soa ainda atual pois desestabiliza as fronteiras entre arte e documento, museu e biblioteca, ler e ver, artista e espectador.

Lembramos que há quase um século Marcel Duchamp reuniu seus escritos, projetos e esboços, sem qualquer organização sistemática, em caixas -arquivos considerando-os como parte integrante de uma única obra. Na "Caixa" de 1914 (conhecida como "Caixa Branca"), realizada entre 1913 e 1914 numa caixa ordinária de papel fotográfico Kodak, com tiragem muito pequena (apenas 5 exemplares), reuniu 16 fac-similes fotográficos de suas notas e a reprodução de um desenho. A "Caixa Verde", publicada apenas em 1934, onde se encontra a ideia de um Rembrant como um artefato doméstico, surgiu simultaneamente à sua obra mais importante "O Grande Vidro" (1915-23). Ali estão reunidos um conjunto de pensamentos, desenhos e textos. Tais notas ampliam a compreensão daquela obra hermética e inter-relacionam vários trabalhos anteriores. Sem apoiar-se numa ordem sistemática, ou seja, fora da lei da classificação, as notas de Duchamp compõem uma poética que articula textos e imagens, pensamentos visuais e poesia, inventários e invenções.

Sua lógica, se é que se pode falar assim, articulase mais ao acaso do que a qualquer outro sistema classificatório. Esse conjunto de notas despertou o interesse de vários artistas, entre eles o inglês Richard Hamilton que se prontificou a traduzir tipograficamente a "Caixa Verde" nos anos 1960, com a supervisão do próprio Duchamp. ${ }^{2}$

Imediatamente após a "Caixa Verde" ser publicada numa edição de 300 exemplares, Duchamp inicia a preparação para a "Caixa em Valise", realizada numa série de edições. A "Caixa em Valise" é uma espécie de dobradiça conceitual instalada entre as ideias expressas nas notas e o concreto dos trabalhos. Para a primeira edição (de luxo) das valises, vinte maletas portáteis de couro foram realizadas e réplicas cuidadosamente arranjadas em seu interior. Incluiu aí repro- duções fotográficas e miniaturas, além de uma obra única e original. Mais tarde, entre os anos de 1950 e 60, foram reproduzidas mais seis séries e a maleta original foi substituída por uma Caixa.

Na "Caixa em Valise" (1935-41), Marcel Duchamp realiza a fusão do arquivo com a exposição. Ao catalogar e realizar miniaturas de um conjunto antológico de seus trabalhos, Duchamp opera na construção de um museu portátil, uma espécie de arquivo móvel e reproduzível para exibição. Constrói assim uma plataforma de interseção entre a obra e sua informação, dialeticamente situada entre o museu e o arquivo, a cópia e o original, mesclando dessa maneira artistas, arquivistas e curadores. A reprodução e a exibição são princípios operantes na construção desse museu portátil que também lança luz sobre as políticas envolvidas na percepção como uma elaboração que envolve variantes históricas, políticas e sociais.

O filósofo alemão Walter Benjamin, contemporâneo de Marcel Duchamp, trabalhava também naquele mesmo momento na construção de um grande arquivo, elaborando uma coleção de textos, aforismos, ideias e citações, que viriam a compor o seu "Trabalho das Passagens". Realizado desde 1927 até sua morte em 1940, Benjamin recolhe fragmentos de textos próprios e de outros autores sobre assuntos diversos para compor uma espécie de pré-história da modernidade. A iluminação a gás, a arquitetura de ferro, as grandes exposições, a moda justapõem-se em seu arquivo. As imagens de pensamento de Benjamin são parte de seu acervo pessoal de memórias e em "Escavando e Recordando" nota a importância do "lugar" nos achados "arqueológicos" e escreve: "aquele que faz um simples inventário de seus achados e falha em estabelecer a localização exata de onde, no solo atual, os antigos tesouros foram encontrados, perde o mais rico prêmio" (BENJAMIN, 1987, p.239).

O conceito de "topicalidade" aí expresso é fundamental no trabalho arquivístico e arqueológico de Benjamin ${ }^{3}$. No caso da pesquisa de acervos, essa noção sugere a importância do estudo das variáveis históricas e institucionais para a compreensão de obras onde as exposições têm papel privilegiado.

No limite, o que interessava a Benjamin era construir, por meio da montagem de fragmentos (pro- 



Clemente Padín

Los Huevos Del Plata. Montevidéu (Uruguai): "El Timón"

Editions, Dezembro/1965

Novembro/1969. 15 números. 22 × 22 cm.

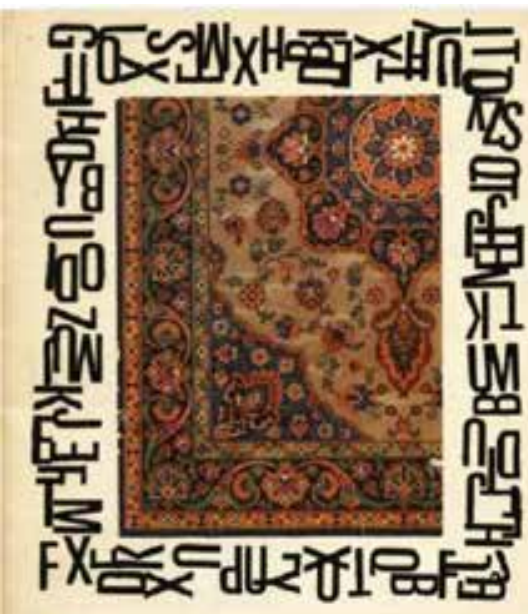

OVIM IO

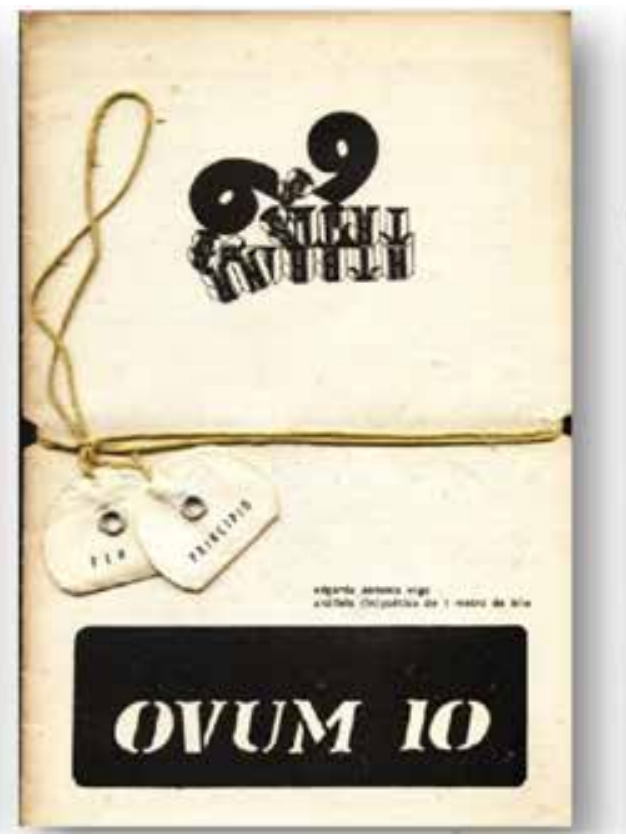

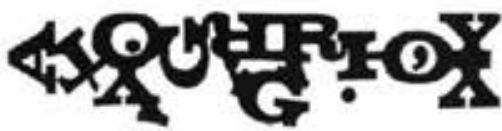
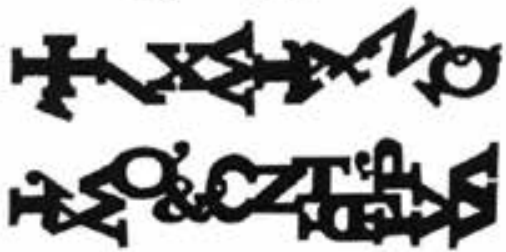

Derosicion Dor ausmra or u matra rotha

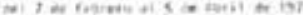

serasis v

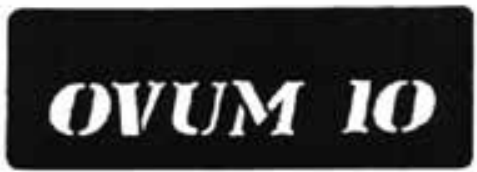

Clemente Padín

OVUM10. Montevidéu (Uruguai): Artegraf. (1967-1972).

10 números. 15.5 x $21.5 \mathrm{~cm}$.

cedimento que pode se comparar ao cinema, à pintura cubista e à curadoria que Duchamp fez de sua obra na "Caixa em Valise"), uma história política da percepção.

Do mesmo modo, a distinção entre obra de arte e documento desde Duchamp, como sabemos, não é mais retiniana. Assim, tomar o valor de exibição e as variáveis institucionais agregados (FREIRE, 1999) como plataformas privilegiadas de pesquisa e prática curatorial supõe, necessariamente, investigar a condição de visibilidade (ou invisibilidade) de artistas e obras.

O valor de exibição está postulado no clássico ensaio de Benjamin "A obra de arte na época de sua reprodutibilidade técnica". Para o filósofo, a passagem do valor de culto ao valor de exibição transforma os modos de produção e recepção da arte, que passam da esfera religiosa (valor de culto) à práxis política (valor de exibição). Ou seja, para além da investigação sobre a obra, as exposições e os contextos em que aparecem (de novo a operação do readymade de Duchamp é exemplar) tornam visíveis tanto as condições sociais, políticas e econômicas em que tais itens entraram nas coleções e /ou foram vistos, quanto concretizam a intenção do artista que envia seus trabalhos para o museu, por exemplo, na expectativa que sejam vistos. A reprodução é ponto nuclear no já citado ensaio de Benjamin escrito entre 193536, (mesmo momento em que Duchamp montava suas "Valises") e torna-se ainda fundamental para 
de multiplicação como princípio (...). Inclui livros de artista, revistas e jornais de artista, edições de fotos, cartões postais, stickers, selos, cópias Xerox, selos, obras sonoras (editadas em discos, cassetes e áudios), rádio arte, edições multimídia em CD-ROM e DVD, vídeos de artistas e filmes e, por fim, net art e computer art".

Tais práticas misturam-se formando híbridos de difícil categorização que passam a circular em outras redes, muitas ainda a serem mapeadas e melhor compreendidas, como é o caso da arte digital que se encontra ainda, creio eu, na fase de elaboração de um vocabulário crítico consistente. No entanto, é a pertinência em diferentes circuitos de comunicação em momentos distintos que melhor define essas práticas. Ao longo da década 1970, por exemplo, as publicações de artistas na forma de revistas de fatura precária e reproduzidas de maneira quase artesanal foram abundantemente distribuídas pelo correio e ao circularem entre muitos países funcionaram como um fórum aberto de trocas. Na América Latina, hoje, tais publicações compõem os relatos fragmentários de uma sorte de história subterrânea.

O tema da catástrofe, vivido por Benjamin intensamente no exílio, orientou seu pensamento, sobretudo nas "Teses sobre o Conceito de História". Encontramos um ponto de vinculação entre o pensamento de Walter Benjamin e o destino de muitos arquivos de artistas no Continente Latino Americano. A noção de choque, considerada por Benjamin uma ideia-chave para a crítica da cultura, ajuda a compreender a dinâmica (ainda ativa) de fragmentação e desaparecimento de arquivos de artistas na Argentina, no Uruguai, Chile e também no Brasil desde os anos de 1960 e 70. No Uruguai, por exemplo, Clemente Padín ao ser preso pela ditadura em 1977 teve seu arquivo confiscado e destruído pela polícia por ser considerado subversivo. Outros artistas como o chileno Guillermo Deisler, que partiu para o exílio na Europa Oriental, também teve seu arquivo fragmentado. $\mathrm{Na}$ Argentina, o arquivo de "Tucumán Arde", mantido pela artista Graciela Carnevale, é um exemplo de resiliência.

Carnevale relata que durante a ditadura se viu forçada a adotar critérios peculiares de preservação para o material recolhido e guardado desde sua participação em "Tucumán Arde". Observa a artista: "o critério que finalmente adotei foi preservar apenas aquilo que tinha estado público. Preservei o que havia sido público e destruí, entre outras coisas o caderno de reuniões, onde muitas vezes apareciam as vozes dos protagonistas, debates e discussões que haviam ocorrido no interior do grupo, ou em alguma correspondência (...)" (apud FREIRE; LONGONI, 2009, p. 13-23). E prossegue: "esse arquivo tem a ver com uma experiência, com um acontecimento breve, porém, intenso onde nossas buscas passavam por questões que nos envolviam como sujeitos e como artistas. Poderia descrevê-los como uma intensidade tal que viver convertia-se numa experiência estética (...)".

Ou seja, o que se nota é um destino comum desses arquivos de artistas, criados como lugar de memória extraoficial, quando o caráter documental da produção artística nessas décadas aliou-se à abrangência da arte postal.

A relação arquivo-exposição cresce no mesmo movimento em que a história da arte é revisada e passa a incluir artistas e movimentos pouco conhecidos e apresentados até há pouco tempo. Hoje, esses arquivos são também ressignificados e vários artistas recuperados para a história hegemônica no momento em que valores de mercado agregam-se a essas coleções, tornando-as ainda mais dispersas e voláteis como itens de consumo.

Em suma, o destino de muitos arquivos de artistas na América Latina nada tem de linear, mas é marcado por sobressaltos e choques para não falar das migrações recentes pelas aquisições internacionais de coleções e arquivos inteiros despatriados e vendidos para museus e coleções metropolitanas.

\section{Arte contemporânea $x$ a priori histórico}

Não é de hoje que a relação entre as práticas artísticas e as instituições estão pautadas no embate. Em 1969, Michel Foucault publica a "Arqueologia do Saber", onde reflete sobre o arquivo como um "sistema de enunciados". E Foucault explica o que entende por arquivo: "não é a soma de todos os textos que uma cultura guardou.... e nem as instituições que os conservam... mas um jogo de relações, (enunciados) que nascem segundo regularidades", ou seja, o arquivo seria um sistema de enunciabilidade (que pode ser dito e o que não pode ser dito) e as regras de seu funcionamento. 

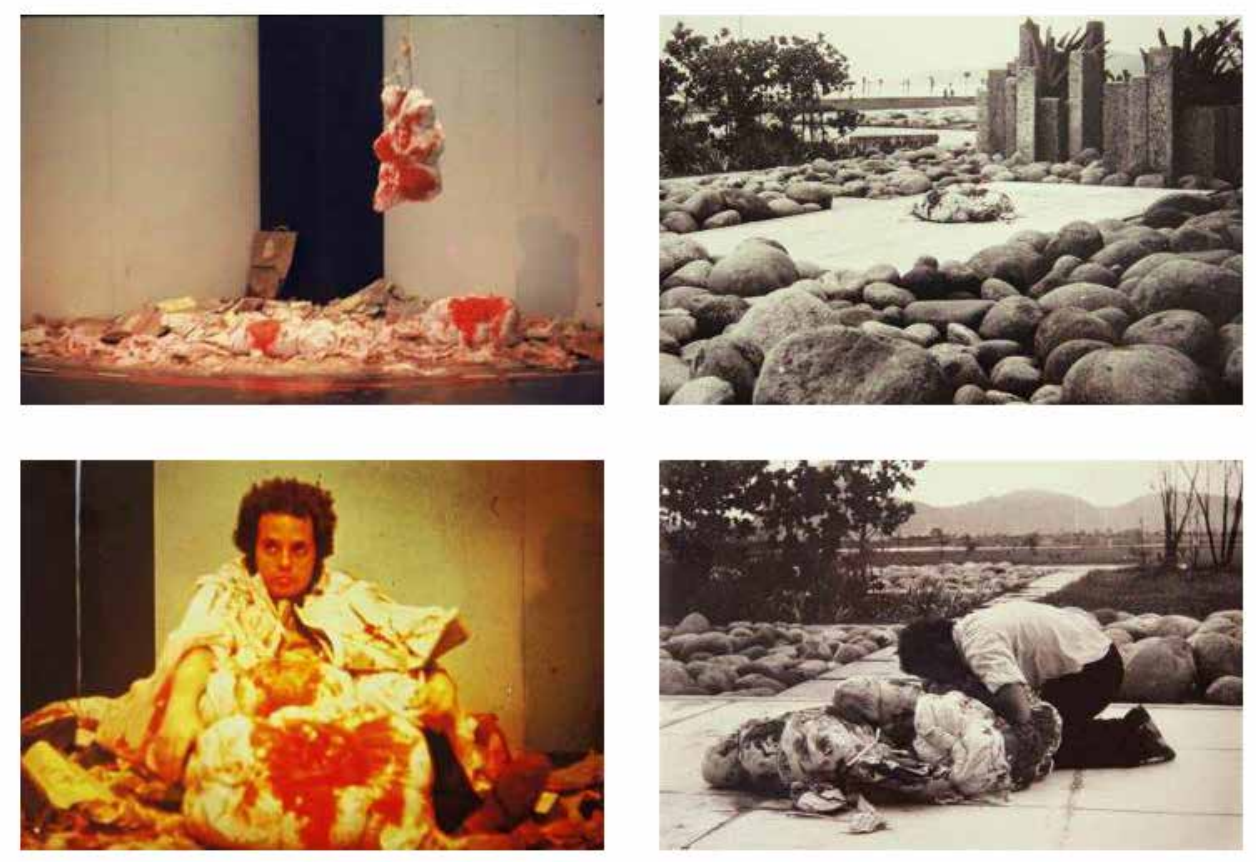

Arthur Barrio

Situação TE - Trouxas Ensanguentadas 1970

Tal empreitada o levou a utilizar o recuo histórico como medida de conhecimento e a arqueologia como referência. Deslocando esse dispositivo conceitual para o compreender a origem e o "a priori histórico" de funcionamento do Museu de arte, veremos que essas constantes de enunciados e práticas estão identificadas a um "inconsciente"4 moderno oriundo da dominante presença do modelo de museu de arte no pós 2a guerra entre nós. No Brasil, é a arquitetura que dá o tom da modernidade e isso implica diretamente no programa e projeto dos museus. Uma espécie de "fator Niemeyer" é decisivo nos processos museológicos brasileiros onde modernização e museus são pares correlatos.

De qualquer maneira, dividem-se em pelo menos três os dispositivos conhecidos do guardar e do narrar nos museus. São eles: a biblioteca, o arquivo e a reserva técnica. Essa separação de lugares físicos e epistemológicos define as práticas nas instituições artísticas e as obras conceituais de caráter documental (as publicações de artistas de forma especial) criam distúrbios nessa lógica sectária.

Se não tinham lugar, até há pouco tempo, cada dia mais os trabalhos conceituais ganham fôlego nas coleções, obrigando a uma revisão das práticas museológicas e arquivísticas mais convencionais. Por outro lado, a modernidade e mais especificamente a crítica modernista solidificou normas de classificação ou sistemas de enunciabilidade traduzidos em critérios, valores, lugares e discursos assentados na autonomia da obra de arte. Isso gerou uma espécie de a priori histórico difícil de transpor na prática cotidiana, quando se lida com a produção contemporânea.

Como sabemos, os paradigmas modernos de classificação e a separação por meios e técnicas são ineficientes e o fluxo entre biblioteca, acervo e arquivo é um dos resultantes dessa ineficácia. Só para ficar num único exemplo, a parceria entre artistas e poetas remonta às primeiras décadas do século passado com as "Palavras em Liberdade", do futurista Marinetti, um dos precursores mais notáveis desse embaralhamento.

\section{Poetas ou artistas: Biblioteca ou reserva técnica?}

No Museu de Arte Contemporânea da Universidade de São Paulo (MAC USP), o desenvolvimento da pesquisa com o acervo conceitual envolveu a observação de um lugar de trânsito entre a biblioteca e a reserva técnica (acervo). Muitas publicações de artistas indicaram esse outro lugar, híbrido e aglutinador, possível de ser aberto, não sem resistência, dentro dos sistemas classificatórios (e exibicionários) disponíveis. Buscamos então brechas para a instauração de um outro tipo de registro e tratamento para tais produções de ca- 
ráter conceitual, que incluem, como vimos, livros de artista, vídeo arte e outras publicações.

$\mathrm{Na}$ biblioteca do museu, o acesso às publicações de artistas torna-se mais fácil e o manuseio, fundamental para os livros de artistas, torna-se possível. No entanto, tal constatação provoca revisões e ampliações em plataformas consolidadas de classificação ${ }^{5}$.

Trata-se, de qualquer maneira, da necessidade de considerar, mais uma vez, nas práticas museológicas, a passagem do objeto autônomo aos processos. Nessa medida, não basta restaurar no museu os objetos em sua fisicalidade, muitas vezes precária, mas, sobretudo, investigar e dar a ver os processos subjacentes à sua circulação $e$ os enunciados que sustentam os espaços de sua legitimação.

Por fim, o curador de coleções, quando não reprime e trata de lançar ao esquecimento obras (como foi feito até há pouco com muito do que foi produzido nos anos 1960 e 70), mas, pelo contrário, orienta sua prática pelos embates críticos, isto é, pelas resistências e dúvidas que certas práticas artísticas provocam nas instituições, deve buscar para enfrentar tal desafio uma maior aproximação entre os artistas e o museu.

\section{Documentação e Narrativa}

A inseparabilidade entre arte e vida, tão importante para a compreensão das poéticas artísticas a partir da segunda metade do século 20 , é o que mais aproxima diferentes proposições documentais tornando-se hoje quase um signo de sua contemporaneidade.

Mesmo frente à predominância da arte de ideias dos anos de 1960 e 70, os projetos de ações e instalações, performances, situações, textos, poesia visual, filmes, projetos de instalação, livros de artistas, arte postal, fotografias de performance etc., existem como materialidade e a interdisciplinaridade que permeia estas linguagens e práticas é, como prenunciou Marcel Duchamp, responsável por situações-limite, na qual a demarcação de um trabalho como "artístico" se dá apenas por sua inclusão num contexto de arte.

Ou seja: como saber se a fotografia de uma ação ou performance é uma obra de arte, ou um documento jornalístico, por exemplo. Como distingui -los? Tal pergunta pode não ser relevante ao visitante, mas é decisiva para o curador de coleções.

A resposta para tal indagação, mais uma vez, deve remeter ao artista, ou seja, é a intenção do artista de exibição de seu trabalho que opera essa distinção.

As fotografias das trouxas ensanguentadas, por exemplo, que foram espalhadas, anonimamente por Artur Barrio em Belo Horizonte em 1970, são conhecidas referências para a história da arte contemporânea brasileira. A indagação de quem as teria feito misturou-se ao clima político que se vivia na época e a associação com os desaparecidos políticos foi imediata. $\mathrm{O}$ anonimato daquela "Situação" reforça essa problematização da mais valorizada categoria das artes: a autoria. Duplamente ausentes, o artista e o público, apenas voltam à cena quando o trabalho se apresenta em exposição. Tal "Situação" de Artur Barrio, perenizada nas fotografias, torna-se antológica mas são poucas as pessoas que puderam testemunhá-la diretamente.

Enfim, quanto maior a indissolubilidade entre arte e vida, mais premente é o registro como prática artística. Além de fotografias, são meios usuais de notação artística esquemas, gráficos e estatísticas, como formas de apresentação de atividades que não seriam acessadas de outra maneira. Ou seja, tais recursos tornam transitiva a relação entre projeto e experiência, testemunho e comunicação. Dessa maneira, a operação artística que trata de documentar exaustiva e minuciosamente um determinado movimento ou fluxo, por exemplo, cria um repertório de dados, de informações parcelares. Nessas práticas singulares, arquivar significa reunir e organizar fragmentos de existência.

Registros podem ainda se apresentar como partituras, isto é, enunciados e textos narrativos propondo ou arrolando ações para uma eventual execução futura. Nesse caso, o documento não se refere unicamente ao passado, mas é no presente que se atualiza na percepção do público. São assim imagens dialéticas pois conjugam o passado de onde provém e o futuro para onde se dirigem.

O museu torna-se esse lugar de transição entre o passado e o futuro, entre a criação individual e a 
sociedade, um objeto transicional, no sentido que Ihe deu Donald Winnicott. Para esse psicanalista inglês, que estudou o desenvolvimento psíquico e afetivo das crianças, o "objeto transicional", ou seja, aquele cobertor ou ursinho de pelúcia que as crianças não soltam, funcionaria como um objeto de passagem ou trânsito, a meio caminho entre o subjetivo e o objetivo, um objeto físico, mas, principalmente, um lugar simbólico de fricção entre as fantasias e criações subjetivas e o mundo exterior socializado.

Essa ampliação no campo de aplicação de um conceito da psicanálise não é estranha à crítica da arte contemporânea. Ao discutir o museu e o arquivo na cultura contemporânea, Hal Foster (1996, p. 97119) opera com o conceito de "cultura visual". Isto é, considera as implicações subjacentes implícitas ao movimento de passar do campo da "história da arte" para a "cultura visual", em cada um de seus termos: da "história" para a "cultura" e da "arte" para o "visual". Como nota esse autor, a passagem da história para a cultura toma a antropologia como discurso privilegiado e a passagem da arte para o visual toma como princípios norteadores a psicanálise e os imperativos da tecnologia. Isso porque a imagem é tomada como projeção e tem implicações na área psicanalítica (inconsciente) e no registro tecnológico (simulacro), princípio esse operativo do banco de dados.

Pergunta Foster: não estaria a cultura visual apoiada em técnicas de "informação" que transforma, por sua vez, uma imensa gama de meios num sistema de imagem-texto; um banco de dados de termos digitais, um "arquivo sem museus"? E prossegue: há um tempo necessário para que essas mutações epistemológicas possam ser assimiladas. Já implícito na pedagogia do projetor de slides, o efeito discursivo do uso das reproduções não havia sido pensado até os anos 1930. Quais seriam "as précondições eletrônicas da cultura visual e quanto tempo ainda deverá levar para que possamos alcançar suas implicações epistemológicas?.

Se os arquivos digitais são a forma tecnológica considerada mais atual e segura de se manter documentos, como compreender essa passagem da obra em sua materialidade à informação virtual, no contexto do museu? Em que medida os arquivos articulam-se às exposições e como processar o alcance desses outros enquadramentos da história e da memória?

\section{Banco de Dados x Narrativa}

O museu configura-se a cada dia como uma zona de contato privilegiada que articula banco de dados e narrativas. Do ponto de vista do trabalho curatorial, as narrativas subjacentes à produção e circulação das obras presentes nas coleções sugerem outros parâmetros, certamente não retinianos, para compreender a relação peculiar entre documento e obra de arte. Para tanto, a pesquisa é fundamental. Há que investigar, portanto, junto aos próprios artistas, seus pensamentos e ideias latentes nas obras. Nos arquivos de instituições, as histórias das exposições e as trajetórias de legitimação em suas múltiplas órbitas. Tais relatos advindos da investigação deverão ser mais uma vez reinvestidos de um potencial narrativo e multiplicador pela percepção do público.

A narrativa, observa Boris Groys (2008), isto é, o recurso à história e à memória, é fator de diferenciação entre seres aparentemente iguais, e esse recurso aparece com clareza em alguns filmes de ficção científica. No filme "Blade Runner", de Ridley Scott (1982), a replicante Rachael, para comprovar quer era um ser humano "real", precisou apropriar-se de uma história. Ou seja, a distinção entre o vivo e o artificial é estabelecida pela narrativa e tal diferença não pode ser observada visivelmente, somente contada, apresenta-se como história.

"A arte como documentação como forma de arte só poderia desenvolver-se sob as condições de nossa 'era biopolítica', no qual a própria vida tornou-se objeto de intervenção técnica e artística" escreve Groys.

Já faz tempo que a mediação com a vida se faz a partir de aparatos tecnológicos. Há muito tempo os médicos não conversam mais com seus pacientes, não escutam suas histórias, mas se aproximam deles numa distância mediada por dados colhidos tecnicamente: raio $X$, imagens digitais, ultrassonografias, cintilografias; ou seja, dados que evidenciam a vida traduzida em imagens e números.

Em suma, os arquivos, em especial os arquivos digitais, são parte dessa nossa vida cotidiana, incessantemente registrada, arquivada e também distribuída em fotografias e textos em sites de relacionamento. O privado e o público confundem- 
se, diariamente, nesses espaços virtuais, onde o banco de dados é fundamental como matéria de criação e imaginação. É certo que esse potencial criativo individual convive com a coleta de dados realizada continuamente pelos sites de busca na rede que alimentam de informações as empresas congregadas e possibilitam, cada vez mais, o controle à distância dos sujeitos-consumidores.

O armazenamento de informações, próprio ao banco de dados na rede, opera com a fragmentação e a dispersão, princípios que também repercutem na percepção. $O$ tempo de busca de informações deve ser veloz e a leitura que as telas dos computadores propõem também é transversal e imediata. Dispersas em hyperlinks, as informações se multiplicam em relações instantâneas de duração limitada, onde um site visto pode, em seguida, desaparecer. A vida média de um site, segundo estudiosos do assunto é no máximo quarenta e quatro dias.

O banco de dados vem sendo considerado o princípio político, epistemológico e sensível de nossa época. Para o artista e teórico russo Lev Manovich (2005), o banco de dados como possibilidade de ver, organizar e imaginar o mundo conseguiu suplantar o cinema e o romance, característicos do século passado.

Isso porque a rede mundial de computadores, como arquivo universal e plataforma aberta, agrega sites estruturalmente incompletos e novos links são continuamente acrescentados aos que já estão lá, enquanto novos elementos são acrescentados e justapostos aos encontrados. O resultante é uma coleção de dados transitória e um tanto caótica, porém distante de qualquer história linear com começo, meio e fim. Nos museus, por outro lado, pela presença e permanência das coisas no universo sensível da experiência, a percepção do visitante poderia operar desfragmentando, imaginando, recordando e refletindo criticamente sobre o que vê. Além disso, pelo caráter documental das práticas artísticas conceituais, que supõe como vimos uma espécie de narrativa latente, potencialmente capaz de comparar tempos e lugares.

Com a privatização da cultura no mundo globalizado, o museu, mais especialmente o museu público, torna-se um lugar estratégico para uma compreensão mais ampla dos sentidos da proção e das características da circulação artística, especialmente no Brasil. Seria potencialmente possível construir, a partir desses museus, outros enquadres críticos para ampliar e rever as análises disponíveis, aprofundando os estudos circunstanciados de artistas, obras, exposições e arquivos, especialmente frente à constatação que a pressão do mercado global força uma espécie de homogeneização. Como observa Boris Groys (2008), o global media market carece de memória histórica e, portanto, não possibilita que o espectador compare o passado com o presente e determine o que é genuinamente novo e contemporâneo. Esse é um dos sentidos mais amplos que articulam acervo, pesquisa, exposição e ensino num museu público e universitário. Ou seja, se acervo de imagens que circula na rede mundial de computadores é homogeneizado qualitativamente pelo sistema global de comunicação de massas e pelo mercado, os arquivos de museus, pelo contrário, são, ou poderiam ser, mais heterogêneos e múltiplos.

Assim, torna-se urgente e necessário garantir no museu público esse lugar onde o vocabulário visual da comunicação de massas pode ser criticamente comparado a outros legados artísticos, sempre abertos a diversas narrativas.

\section{Notas}

1. Trabalho apresentado no Ciclo de Palestras "Colecionismo de Artistas em Museus de Arte", organizado pela Pinacoteca do Estado de São Paulo, em agosto de 2012.

2. Ver: Hamilton, Richard. The Bride Stripped Bare by her Bachelor, Even. A typographic version by Richard Hamilton of Marcel Duchamp's Green Box, Trad. George Head Hamilton. Nova York: Percy Lund, Humphries et co. 1960.

3. MARX, Ursula; SCHWARZ, Gudrun; SCHWARZ, Michael; WIZISLA, Erdmut (Eds.). The Walter Benjamin's Archive. London: Verso, 2007.

4. Ver: Freire, Cristina. O Inconsciente Moderno do Museu Contemporâneo no Brasil. In: Colóquio Internacional História e $(m)$ movimento. São Paulo: Museu de Arte Moderna de São Paulo, 2008, p. 38-49.

5. O esforço da bibliotecária do MAC USP, Lauci 
Bortoluci, para atender às demandas da pesquisa tem sido incluir as várias categorias de "publicações de artista" nos catálogos do SIBI (Sistema Integrado de Bibliotecas da Universidade de São Paulo).

\section{Referências}

BENJAMIN, Walter. Obras Escolhidas. Vol. II. São Paulo: Brasiliense, 1987.

DE DUVE, Thierry. Resonances du Readymade. Duchamp entre avant-garde et tradition. Nêmes: Edition Jacqueline Chambon, 1989.

GROYS, Boris. Art in the Age of Biopolitics: From artwork to art documentation. In Art Power. Cambrige: Mit Press, 2008.

FOSTER, Hal. The archive without Museums. October, vol.77, Summer, 1996.

FREIRE, Cristina. Poéticas do Processo. Arte Conceitual no Museu. São Paulo, lluminuras, 1999.

FREIRE, Cristina; LONGONI, Ana. Conceitualismos do Sul. São Paulo: Editora Annablume, 2009.

MANOVICH, Lev. The Database. In: KOCUR, Zoya; LEUNG, Simon (Orgs.). Theory in Contemporary Art since 1985. [Hoboken, New Jersey ]: Blackwell Publishing, 2005.

\section{Sobre a autora}

Cristina Freire é professora Titular e Curadora do Museu de Arte Contemporânea da Universidade de São Paulo. É docente do Programa de PósGraduação Interunidades em Estética e História da Arte da Universidade de São Paulo. Coordenadora do GEACC - Grupo de Estudos em Arte Conceitual e Conceitualismos no Museu - CNPq. Vice Diretora do MAC USP (2010-2014). Sua produção acadêmica inclui textos em publicações nacionais e internacionais e os livros: Além dos Mapas: Monumentos no Imaginário Urbano Contemporâneo (ed. Annablume, 1997); Poéticas do Processo. Arte Conceitual no Museu (ed. lluminuras, 1999); Arte Conceitual, (ed. Jorge Zahar Editor, 2006); Paulo Bruscky. Arte, Arquivo e Utopia (ed. CEPE, 2007); Walter Zanini: Escrituras Críticas (ed. Annablume/ MAC USP, 2013), entre outros. 